\title{
Organizational-technological modeling of a multi-apartment residential house where overhaul is planned
}

\author{
Rustam Fatullaev* \\ Moscow State University of Civil Engineering, Yaroslavskoe shosse, 26, Moscow, 129337, Russia
}

\begin{abstract}
Using the potential of carrying out unscheduled repairs as a tool for evaluating the effectiveness of organizational and technological solutions is most effective when planning the overhaul of apartment buildings. In order that the potential obtained as a result of calculations could give the most objective assessment of organizational and technological solutions when carrying out unscheduled repairs, it is necessary to form an organizational and technological model of the object. This model gives a quantitative assessment of the influence degree of the constraint parameters and allows selecting the most effective organizational and technological model for the repair and construction works.
\end{abstract}

\section{Introduction}

Modern valuation principles of organizational and technological solutions for carrying out unscheduled work on the overhaul, do not impose proper requirements for taking into account all the main factors and parameters when evaluating the effectiveness of carrying out certain works. At the same time, the tool for evaluating the effectiveness of work on the overhaul should be easy to use, expressed in quantitatively deterministic values.

The introduction of the potential for unscheduled work during the period between repairs, allows to take into account the polyparametricity of the object of study. The method of calculating the potential can help not only residents in determining the required list of works during the overhaul period, but also in determining the priority of work when planning a comprehensive overhaul. To calculate the quantitative value of the potential for unscheduled repairs, as a part of the the study, apartment buildings are presented in the form of an organizational-technological model created on the basis of a system of parameters.

The potential of organizational and technological processes of construction production were studied and integrated by such scientists as A. Lapidus, D. Topchiy, A. Goncharov, A. Makarov, P. Govorukha [1-5].

The purpose of this study is to develop an organizational-technological model of the object, in which it is planned to conduct an unscheduled overhaul, to conduct an experiment

\footnotetext{
* Corresponding author: FatullaevRS@mgsu.ru
} 
devoted to the study of the dependence of the potential for carrying out unscheduled repair work on organizational-technological solutions.

\section{Methods}

A model is a combination of logical, mathematical, or other relationships that display, with a necessary and sufficient approximation to reality, certain characteristics and parameters of the system [2]. The basis for the formation of organizational and technological systems is the use of a functional system approach, which allows you to structure this system for its further practical application [2,3]. The organizational-technological system consists of separate, but interrelated elements - subsystems. Subsystem - a combination of elements of the system, interconnected among themselves and performing a relatively independent task (several tasks) related to the goal of achieving the goals of the system [4].

System is a complex of selectively included elements that interact with each other to achieve a given useful result, which is taken as the main system-forming parameter [2,5].

In the modeling of difficult systems, the theory of functional systems is used, it makes it possible to assess the adequacy of the model by the degree of reliability. The formation of a hierarchy of subsystems should be carried out in the form of a hierarchy of results in order to open up a way of connecting separate hierarchical levels. Usually, subsystems are heterogeneous, and each heterogeneous element has a functional sense in the formation of final results. In such subsystems distinguish their heterogeneous elements, considered in unity and within the system itself $[1-3,6-9,12,14]$.

The specific scientific methodology of each system and, accordingly, the practices it serves, is revealed through specific, relatively independent approaches or principles. In this case, the target is a criterion-constraint. The goal is to get the result of the specified parameters. Criterion - the characteristic and description of specific parameters. Restrictions - the degree of freedom within a given system [10,11].

For the case proposed in the case study, the organizational-technological system compliance with the result of a set of eight subsystems (parameter weights). Accordingly, the main goal is to identify subsystems with certain limitations that ensure the achievement of goals [2].

As a rule, the study involves the consideration of the elements of the system as separate subsystems. Subsystems are represented as an indivisible part of the system and allow to achieve a local result leading to the overall result. Subsystems are considered as a set of system elements that are interconnected and perform a relatively independent task (several tasks) to achieve the goal of the system as a whole. It is known that there is a methodological concreteness, which consists of: a goal - a criterion - a constraint. The goal is the result; criterion - a sign that matches the result; restrictions - the degree of freedom necessary to achieve a result.

In this case, the composition of the organizational-technological system includes eight subsystems (parameters). Achieving the result is a combination of eight subsystems that determine the degree of compliance with the desired result. Limitations exist for subsystems that define the domain of definition of the system being modeled. Therefore, the main task is to identify subsystems with restrictions that are necessary to achieve the stated goals. Then the definition of the functional purpose of each subsystem and the identification of their limitations is required.

The parameters affecting the choice of organizational-technological solutions proposed include:

- Energy efficiency of enclosing structures - maintaining comfortable microclimate parameters in residential premises is one of the main parameters influencing the decision to conduct unscheduled repairs. The most significant parameter is the increased consumption 
of energy resources to ensure comfortable conditions, which entails an increase in the cost of utilities, and accordingly an increase in the financial burden on the homeowner [5];

- Physical deterioration of structures (sometimes referred to as material or technical) gradual partial or complete loss of the building or its element over time with the initial qualities as a result of the impact of climatic factors and human activity, i.e. deterioration in operational properties and decrease in cost. Depreciation depends on the durability of fixed assets; material quality; raw materials of which the product is made (design); intensity of use and technological processes; the quality and modernity of inspections and repairs; worker qualifications; climatic conditions, etc. The intensity of physical deterioration of a structure depends on the type of production: loads and conditions of maintenance: effects of nature on them (temperature, humidity, etc.) [5];

- Physical wear of engineering networks and equipment - similar in nature to the previous parameter. The main distinctive features are critical values of the degree of wear and a much higher degree of maintainability of networks and equipment. In assessing the technical condition of engineering equipment of buildings and structures, the amount of physical wear is established. This parameter at the time of its assessment is expressed as the ratio of the cost of objectively necessary repair measures, eliminating damage to engineering equipment, and their replacement cost. Physical deterioration of systems or their sections is assessed by comparing signs of wear identified as a result of visual and instrumental examination with their values given in regulatory documents [5];

- Security level - a parameter that reflects the degree of protection of residents from external socio-cultural and technological impacts. The significance of this parameter was given by the fact that a person has long since found a place in a dwelling in which he is protected from climatic and socio-cultural influences, which is a natural human need. With the development of technological progress, the living space, in particular the residential house, has acquired a complex multi-purpose system that provides a comfortable stay and operation (elevators and other lifting mechanisms, access systems, etc.). In this regard, more and more new measures are required to maintain the level of security. The means of increasing the level of security include: a house intercom; concierge; remote alarm systems; video surveillance systems; fire alarm and smoke removal systems [5];

- Moral depreciation of structures is a reduction in replacement cost due to a decrease in reproduction costs or a difference in the cost of a building during the construction period and at the current time (the first form, or the first kind of obsolescence). Obsolescence depends on scientific and technical progress. Technological aging causes the need to improve the improvement of the building (or apartment) or technical equipment, which increase the cultural and living standard of the residents and reduce labor costs during the operation of the building. The appearance of effective building materials, structures or more advanced architectural and engineering solutions does not lead to the "obsolescence of the house" in the inexpediency of its further use [12]. You can talk about the obsolescence of those elements, technical and building, which create more favorable conditions for living or facilitate the work of the personnel of operational services: the use of more advanced paint and varnish coatings, heat and sound insulation materials for partitions, automatic control of elevators, etc [5];

- Obsolescence of engineering networks and equipment - this parameter is a special case of obsolescence and is typical for building and drainage systems, heating equipment, fittings and heating and hot water supply networks, ventilation and air conditioning systems. Examples of the presence of obsolescence of utilities include: the emergence of more modern equipment of sanitary facilities in apartments, gas and electrical equipment, hot water supply, thermal control of heating, the introduction of pipes and sanitary equipment made of metal-plastic materials [5]; 
- Consumer quality - housing stock objects are divided by consumer quality into the following classes: economy; comfort; business; elite. It is advisable to differentiate the housing stock by the quality of such parameters as the material of supporting and enclosing structures, interior materials, engineering support, improvement of the adjacent territory, area of residential premises, etc. Over time and in connection with possible unpredictable modes of operation, it is possible to change the actual level of consumer quality. These circumstances may cause the need for additional measures to help maintain or restore the original consumer quality [5].

\section{Results}

To determine the weights of the parameters of the organizational-technological model, we will use one of the most optimal methods of mathematical statistics - the variational series method [13,14]. As a source of statistical data, we take a table of ranking results, while we will assume that the total weight of all indicators is equal to 1 .

The first stage involves the calculation of the arithmetic mean value of the variation series using the formula:

$$
\bar{u}=\frac{1}{m} \sum_{i=1}^{m} y_{i} n_{i}
$$

where $y_{i}$-points that are set for the $i$-th parameter; $n_{i}$ - number of the $i$-th, which is set by the group of experts to the $i$-th parameter; $\mathrm{m}$ - number of expert groups.

During the second stage, the average arithmetic values of all parameters are summed up:

$$
U=\sum_{j=1}^{p} \bar{u}=\sum_{j=1}^{p} \frac{1}{m} \sum_{i=1}^{m} y_{i} n_{i}
$$

where $U$ - sum of the arithmetic means of the variational series.

The purpose of the third stage is to determine the weight of each parameter:

$$
W_{i}=\frac{\frac{1}{m} \sum_{i=1}^{m} y_{i} n_{i}}{U}
$$

After all these steps, using the data on the parameters obtained in the experimental part of the study [5], it has become possible to obtain the values of the weights of the parameters.

The results of the calculations were summarized in a table of parameter weights (Table 1).

Table 1. Parameter group weights

\begin{tabular}{|c|c|c|c|c|c|c|c|}
\hline$W_{1}\left(x_{1}\right)$ & $W_{2}\left(x_{2}\right)$ & $W_{3}\left(x_{3}\right)$ & $W_{4}\left(x_{4}\right)$ & $W_{5}\left(x_{5}\right)$ & $W_{6}\left(x_{6}\right)$ & $W_{7}\left(x_{7}\right)$ & $W_{8}\left(x_{8}\right)$ \\
\hline 0,25 & 0,19 & 0,14 & 0,13 & 0,11 & 0,08 & 0,06 & 0,04 \\
\hline
\end{tabular}

Thus, the greatest influence (weight) has the parameter $x_{2}$, which reflects the Physical wear of structural elements [5], and the least influence (weight) - the parameter $x_{8}$ Consumer quality of the residential apartments [5]. Similar conclusions were obtained during the analysis of the regression equation of the 2 nd order, that is, confirmation was obtained of the calculated values of the experimental design.

The experiment conducted assumed the consideration of three levels of significance for each parameter $[15,16]]$. However, the open nature of the mathematical model allows for the existence of an indefinite number of levels.

In this case, the following condition should be observed: for the adequacy of the calculated in the early study mathematical model described in the experiment (4) the process needs to bring the total value of the model parameter levels to match with the control points established by the experiment plan.

$$
P_{\text {U.o. }}=T D_{U .0 .} \leq 92
$$

Select the following control points: U1, U16, U25. 
In the point of the plan $\mathrm{U} 1$, in all groups of parameters, indicators of the upper levels of significance are established, $P_{U . O}=92$

In the point of the plan U16, in all groups of parameters, indicators of lower levels of significance are established, $P_{U . O}=43,56$

In the point of the plan $\mathrm{U} 25$ in all groups of parameters the indicators of the main (zero) significance levels are set, $P_{U . O} .=54$

Since the total value of the weight of the parameters of the organizational-technological model is assigned a value of 1 , to bring the mathematical model into compliance with the experimental data, we set the values of the various levels of the parameter of the organizational-technological model equal to: lower - 43.56; main - 54.0; the top one is 92 . In this case, the mathematical model allows constructing a function for approximating a regression curve.

Given the above, we will complete table 2. 
Table 2. The levels of the parameters of the organizational and technological model of the facility overhaul and their values

\begin{tabular}{|c|c|c|}
\hline $\begin{array}{c}\text { Parameter name, } \\
\text { symbol }\end{array}$ & Parameter levels & $\begin{array}{c}\text { Parameter } \\
\text { value }\end{array}$ \\
\hline \multirow[t]{9}{*}{$\begin{array}{l}\text { Energy efficiency of } \\
\text { enclosing } \quad \text { structures, } \\
x_{1}\left(P_{1}\right)\end{array}$} & $\begin{array}{l}\text { The deviation of the value of the actual specific annual } \\
\text { consumption of energy resources from the base level is } \\
\text { more than }+50 \%\end{array}$ & 0,0 \\
\hline & from +50 inclusive to +25 & 16,65 \\
\hline & from +25 inclusive to 0 & 33,27 \\
\hline & from 0 inclusive to -15 & 43,56 \\
\hline & from -15 inclusive to -30 & 53,23 \\
\hline & from - 30 inclusive to -40 & 59,89 \\
\hline & from - 40 inclusive to -50 & 66,24 \\
\hline & from -50 inclusive to -60 & 78,98 \\
\hline & - 60 inclusive and less & 92 \\
\hline \multirow{6}{*}{$\begin{array}{l}\text { Physical deterioration of } \\
\text { structures, } x_{2}\left(P_{2}\right)\end{array}$} & The state is dilapidated, PD $61-70 \%$ & 0,0 \\
\hline & Unsatisfactory condition (below average), PD 41-60\% & 15,33 \\
\hline & Not quite satisfactory, PD 31-40\% & 43,56 \\
\hline & Satisfactory, PD 21-30\% & 48,11 \\
\hline & It is quite satisfactory, PD $11-20 \%$ & 76,23 \\
\hline & Good, PD 0-10\% & 92 \\
\hline \multirow{6}{*}{$\begin{array}{l}\text { Physical deterioration of } \\
\text { engineering networks and } \\
\text { equipment, } x_{3}\left(P_{3}\right)\end{array}$} & The state is dilapidated, PD $61-70 \%$ & 0,0 \\
\hline & Unsatisfactory condition (below average), PD 41-60\% & 15,33 \\
\hline & Not quite satisfactory, PD 31-40\% & 46 \\
\hline & Satisfactory, PD $21-30 \%$ & 61,33 \\
\hline & It is quite satisfactory, PD $11-20 \%$ & 76,66 \\
\hline & Good, PD 0-10\% & 92 \\
\hline \multirow{5}{*}{ Security level, $x_{4}\left(P_{4}\right)$} & The security system is not in an emergency state & 0 \\
\hline & $\begin{array}{l}\text { The presence of one of the complex security systems (fire } \\
\text { alarm) }\end{array}$ & 23 \\
\hline & $\begin{array}{l}\text { The presence of two of the complex security systems (fire } \\
\text { alarm systems, dispatching systems, storage and display of } \\
\text { information) }\end{array}$ & 43,56 \\
\hline & $\begin{array}{l}\text { The presence of four of the complex security systems (fire } \\
\text { alarm systems, dispatching systems, monitoring of } \\
\text { engineering networks at home) }\end{array}$ & 69 \\
\hline & $\begin{array}{l}\text { The presence of five of the complex security systems } \\
\text { (alarms, scheduling systems, monitoring, access control and } \\
\text { rapid response) }\end{array}$ & 92 \\
\hline \multirow{4}{*}{$\begin{array}{l}\text { The complexity of the } \\
\text { methods used to assess } \\
\text { the state of the residential } \\
\text { house } x_{5}\left(P_{5}\right)\end{array}$} & Without applying any techniques & 0 \\
\hline & Visual inspection & 43,56 \\
\hline & Instrumental inspection & 61,32 \\
\hline & Technical inspection & 92 \\
\hline \multirow{4}{*}{$\begin{array}{l}\text { Obsolescence } \\
\text { structures, } x_{6}\left(P_{6}\right)\end{array}$} & Significant loss of practical significance, OS $36-45 \%$ & 0 \\
\hline & Some loss of practical significance, OS $26-35 \%$ & 43,56 \\
\hline & Average obsolescence, OS $15-25 \%$ & 61,32 \\
\hline & Minor obsolescence, OS 0-15\% & 92 \\
\hline \multirow{4}{*}{$\begin{array}{l}\text { Obsolescence of } \\
\text { engineering networks and } \\
\text { equipment, } x_{7}\left(P_{7}\right)\end{array}$} & $\begin{array}{l}\text { Lack of hot and cold water supply, garbage chute, elevator } \\
\text { equipment, telephone communication), OS } 36-45 \%\end{array}$ & 0 \\
\hline & $\begin{array}{l}\text { Lack of hot water supply, garbage chute, elevator } \\
\text { equipment, telephone communication), OS } 26-35 \%\end{array}$ & 43,56 \\
\hline & Lack of hot water supply, garbage chute), OS $16-25 \%$ & 61,32 \\
\hline & $\begin{array}{l}\text { Perhaps the absence of a garbage chute and telephone), OS } \\
0-15 \%\end{array}$ & 92 \\
\hline \multirow[t]{4}{*}{$\begin{array}{l}\text { Consumer quality of } \\
\text { residential house, } x_{8}\left(P_{8}\right)\end{array}$} & $\begin{array}{l}\text { There are significant deviations from the stated consumer } \\
\text { quality of residential house }\end{array}$ & 0 \\
\hline & There are minor deviations from the stated consumer quality & 43,56 \\
\hline & $\begin{array}{l}\text { Consumer quality of residential house corresponds to the } \\
\text { stated }\end{array}$ & 68,7 \\
\hline & Consumer quality of residential house above declared & 92 \\
\hline
\end{tabular}


As a result, it became possible to build a graph (Figure 1), which shows an ideal model of the object where unscheduled overhaul is planned, and the scales of the parameters correspond to their weight. The graph presented in (Figure 1) is cumulative.

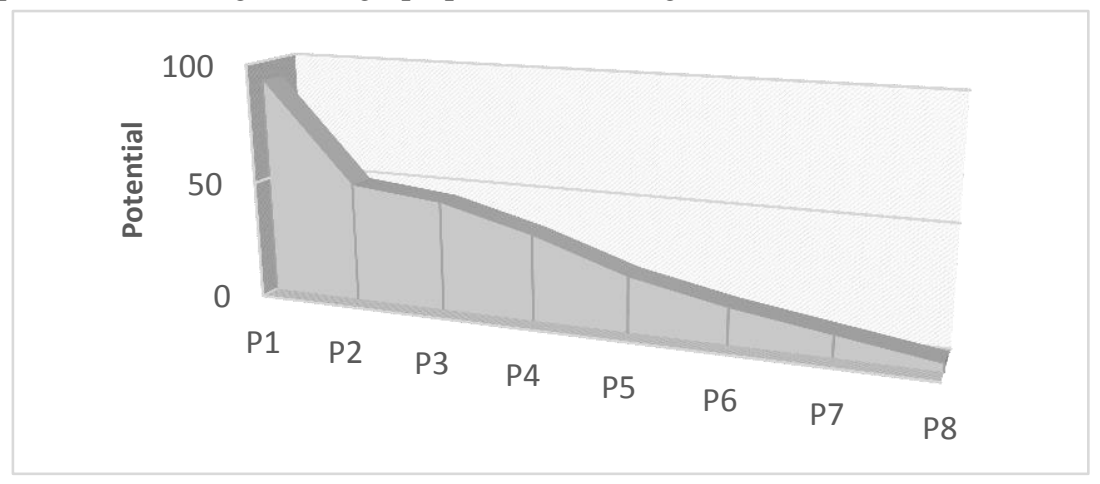

Fig. 1. Graphic interpretation of the ideal model of the facility overhaul

\section{Conclusions}

The developed model allows estimating the degree of the influence significance of the constrained conditions on the carrying out the repair and construction works in apartment buildings. Based on the analysis results, we can draw a conclusion about the most significant parameters, which makes it possible to rationally distribute their efforts to minimize their influence.

It is open, allows to be corrected by introducing, changing, complementing or removing various parameters in accordance with the peculiarities of a particular residential house.

\section{References}

1. A. Lapidus, I. Abramov, Science and Business 10, 17-28 (2017)

2. A.A. Lapidus, A.N. Makarov, Bulletin of Moscow State University of Civil Engineering 8, 150-160 (2015)

3. A.O. Khubaev, Prospects of science 4 (103), 57-61 (2018)

4. V.Y. Mishchenko, D.I, Yemelyanov, A.A. Tikhonenko, Industrial and Civil Engineering 10, 69-71 (2013)

5. R.S. Fatullaev, Components of Scientific and Technological Progress 3(33), 17-22 (2017)

6. A. Khubaev, T. Bidov, A. Bzhienikov, V. Nesterova, IOP Conf. Series: Materials Science and Engineering 365, 81-96 (2018)

7. A. Lapidus, T. Bidov, A. Khubaev, MATEC Web of Conferences 117 (2017)

8. Topchiy D.V., Shatrova A.I. International Journal of Mechanical Engineering and Technology, 4, 539-547 (2018)

9. M. Liu, G. Ballard, Proceedings for the 16th Annual Conference of the International Group for Lean Construction, Planning and Control 1, 657-666 (2008)

10. L. Floreza, J.C. Cortissoz, Procedia Engineering 164, 42 - 48 (2016)

11. A.A. Fard Fini, T.H. Rashidi, Journal of Construction Engineering and Management 1, 28-41 (2016)

12. Khubaev A., Bidov T., Rybakova A., MATEC Web of Conferences 27, 27th R-S-P Seminar, Theoretical Foundation of Civil Engineering (27RSP), TFoCE 201804071 (2018) 
13. Lapidus A.A., Govorukha P.A. International Journal of Applied Engineering Research 20, 40946-40949 (2015)

14. Topchiy D., Tokarskiy A. IOP Conference Series: Materials Science and Engineering 21, Construction - The Formation of Living Environment, 062005 (2018)

15. Abramov I.L., Lapidus A.A. Construction - The Formation of Living Environment conference proceedings, 062002 (2018)

16. Topchiy D., Skakalau V., Yurgaytis A. International Journal of Civil Engineering and Technology, 1, 985-993 (2018) 